\title{
Job Satisfaction Scores of Lebanese and Jordanian Nephrologists and Their Association with Age, Gender, Workload and Income
}

\section{Mabel Aoun ( $\square$ aounmabel@yahoo.fr)}

Saint Joseph University: Universite Saint-Joseph https://orcid.org/0000-0001-9893-5514

Nour Breiteh

American University of Beirut

Kassem Kassak

American University of Beirut

\section{Research}

Keywords: Nephrologist, job satisfaction, payment model, workload, gender, Eastern-Mediterranean Region.

Posted Date: October 21st, 2021

DOI: https://doi.org/10.21203/rs.3.rs-966682/v1

License: (c) (i) This work is licensed under a Creative Commons Attribution 4.0 International License. Read Full License 


\section{Abstract}

BACKGROUND: The main challenges that nephrologists are facing worldwide are lower income, dissatisfactory payment models, long work hours and burnout. This study aimed to identify factors associated with nephrologists' satisfaction in Lebanon and Jordan.

METHODS: A survey was sent to Lebanese and Jordanian nephrologists about demographics, job satisfaction (5-Likert scale), workload and reimbursement.

RESULTS: Sixty-seven nephrologists responded, 59 were complete. Mean age was $46.9 \pm 12.5$ years, $39 \%$ women. Mean total job satisfaction score was 3.39 \pm 0.45 . Respondents reported low rates of satisfaction towards job opportunities (20\%), income (25\%) and administrative support (32\%) and high satisfaction rates in relationship with patients $(78 \%)$ and colleagues $(73 \%) .62 .7 \%$ of respondents were paid fee for service and income was significantly higher among males $(p<0.001)$. Lebanese nephrologists had payment delays of 12 months and it was significantly associated with lower work-life balance $(p=0.038)$. $61 \%$ of respondents worked $>30$ hours weekly and $22 \%$ followed $>40$ dialysis patients. Using regression analysis, older age, working $>10$ hours per week and monthly income $>5000$ US $\$$ were significantly associated with higher total job satisfaction score $(p=0.002,0.004$ and 0.028 respectively). Satisfaction towards income was significantly lower among females $(p<0.024)$. Finally, gender discrimination was significantly perceived by women $(p<0.001)$.

CONCLUSIONS: Younger age, less workload, lower income and payment delays are associated with dissatisfaction among the surveyed nephrologists. Gender differences are significant with lower satisfaction among women. Decision makers need to address payment delays, support women and regulate students' entry to nephrology programs to avoid unemployment.

\section{Background}

Job satisfaction is a widely used indicator of contentment at workplace. In healthcare institutions, it helps assess the well-being and motivation of healthcare providers [1, 2]. Satisfaction of physicians has been shown to be associated with better productivity and improved quality of care [3,4]. In addition, physician's well-being can enhance patients' satisfaction and adherence to therapy $[3,4]$. This has been clearly shown in a recent systematic review that evaluated the impact of physicians' well-being on the quality of care offered to patients [3]. Ultimately, the fulfillment of physicians and patients will contribute to the amelioration of health outcomes [5].

Among all physicians, nephrologists are the most entitled to follow the same chronic patients on the long term. Worldwide, nephrologists are mainly taking care of chronic dialysis patients and to a lesser degree of kidney transplant patients. The job satisfaction of nephrologists may be dependent on several factors and a huge interest emerged in the last years towards strategies that can help preventing nephrologists' emotional exhaustion and burnout [6]. The main challenges that nephrologists are facing worldwide are lower income compared to other specialties, dissatisfactory payment models, long work hours and 
working in different sites [6]. A Japanese survey showed a high dissatisfaction of dialysis healthcare workers secondary to poor salaries and welfare conditions [7]. A survey of US adult nephrology fellows regarding their career choice showed a high rate of dissatisfaction associated with long work hours and low income [8,9]. Moreover, in the last decade and in several countries, there has been an increased governmental intrusion into nephrologists' daily practice through restrictive regulations [6].

In the Middle-East, nephrologists' job satisfaction has never been studied. Factors enhancing their satisfaction may be different between a country and another depending on the number of patients, reimbursement schemes and dialysis unit management. Lebanon and Jordan are two Middle-Eastern countries that differ regarding the ratio of nephrologists to dialysis patients. This ratio is estimated to be 160 / 4200 and 90 / 5000 in Lebanon and Jordan respectively. In Lebanon, although the majority of physicians are reimbursed through private insurances or out of pocket payment [10], nephrologists are among the few specialists that are principally paid by the public sector. In Jordan, the reimbursement of nephrologists depends on both private and public resources. Despite these differences, the two countries have a similar national policy that limits the number of reimbursed dialysis patients to 40 per nephrologist. Therefore, several questions could be raised regarding nephrologists' satisfaction in these countries. There is uncertainty whether nephrologists are satisfied with the limitation to 40 dialysis patients or they would prefer to follow more patients. It is also unclear if they prefer a payment model based on fee for service (FFS) or salary. Understanding the factors that enhance the satisfaction of nephrologists could inform policymakers to establish better strategies for reimbursement and patients' distribution.

The aim of this study is to evaluate the association between different payment models, workload and job satisfaction of nephrologists in Lebanon and Jordan.

\section{Methods}

\section{Population setting and participants}

This study addressed all nephrologists working in Lebanon and Jordan. The Lebanese participants were included if they were registered at the Lebanese Order of Physicians and the Lebanese Society of Nephrology and Hypertension. The Jordanian ones were included if they were registered at the Jordanian Order of Physicians and Jordan Society of Nephrology and Renal Transplantation.

An official request for nephrologists' emails was sent to the two presidents of the Lebanese and Jordanian Societies of Nephrology. The two societies shared these emails directly with the Institutional Review Board (IRB) of the American University of Beirut (AUB). The IRB office gave their approval to upload these emails to the LimeSurvey of AUB.

\section{Questionnaire}


The survey included six sections (Supplementary, Questionnaire). The section addressing job satisfaction was based on a 5-point Likert scale questionnaire that was validated and used for assessment of US nephrologists' career satisfaction [8]. The other sections included questions on demographics and educational background, past and current work, academic activities, workload and payment, and burnout.

The questionnaire was sent to nephrologists' email addresses through the online survey (LimeSurvey) between February and March 2020.

\section{Statistical analysis}

Data was analyzed using SPSS, version 25. Categorical variables were reported as numbers and percentages. Continuous variables were reported as mean and standard variation (SD) if normally distributed and median and interquartile range (IQR) if data were skewed. Chi Square test was used to compare the categorical data between two groups and $t$ independent test used to compare continuous data if normally distributed. Mann-Whitney $U$ test was used to compare medians between two groups when variables are skewed. Cronbach's alpha was used to assess the reliability of the job satisfaction questionnaire. Spearman's Rho coefficient was used to assess the correlation between two continuous variables. Job satisfaction items were reported in two ways: as categorical data divided into satisfied, dissatisfied or neutral; and as continuous data in a scale from 1 to 5 . We used the continuous scale to analyze the association of job satisfaction with other variables. Simple linear regression was used to estimate the association between different job satisfaction components and other variables. $P$-value was considered significant if $<0.05$.

\section{Ethical considerations}

The survey was distributed to all nephrologists working in Lebanon and Jordan, through their respective orders of physicians, hence covering all parts of the two countries without discrimination. This study received the IRB approval of the AUB before releasing the questionnaire online (IRB number SBS-20190481). It followed the general ethical rules of research in public health. Ethical issues that were addressed were confidentiality and privacy of the participants. The electronic questionnaire was submitted anonymously. Nephrologists were informed about the aim of the study, about their right of declining or withdrawing at any time and that by answering the online survey they were giving their informed consent to participate.

\section{Results}

\section{General characteristics and work setting}

Emails were sent to 250 nephrologists. Sixty-seven nephrologists responded to the survey $(27 \%$ of response). Fifty-nine out the 67 participants completed more than $75 \%$ of the questionnaire and were included in the analysis. They were divided into 51 Lebanese and 8 Jordanian nephrologists. Table 1 summarizes the general characteristics of the 59 participants. Their mean age was $46.9 \pm 12.5$ years with 
$39 \%$ of females. The Jordanian group included a majority of males and they were older than the Lebanese sample. 
Table 1

General characteristics of Lebanese and Jordanian nephrologists

\begin{tabular}{|c|c|c|c|c|}
\hline & Lebanese $n=51$ & Jordanian $n=8$ & $\begin{array}{l}\text { Total } \\
\mathrm{n}=59\end{array}$ & $P$ \\
\hline Age & $45.36 \pm 11.24$ & $56.71 \pm 16.12$ & $46.92 \pm 12.46$ & $0.024^{\mathrm{a}}$ \\
\hline Mean \pm SD & $42[36.2-53.7]$ & $56[40-77]$ & $42[37-57]$ & \\
\hline \multicolumn{5}{|l|}{ Median [IQR] } \\
\hline Gender, n (\%) & $22(44)$ & $6(75)$ & $28(47.5)$ & \multirow[t]{4}{*}{$0.207^{b}$} \\
\hline Male & $22(44)$ & $1(12.5)$ & $23(38.9)$ & \\
\hline Female & $7(12)$ & $1(12.5)$ & $8(13.6)$ & \\
\hline \multicolumn{4}{|l|}{ Unanswered } & \\
\hline Years of practice, $n(\%)$ & $11(21.6)$ & $1(12.5)$ & $12(20.4)$ & \multirow[t]{5}{*}{$0.661^{b}$} \\
\hline$<5$ & $20(39.2)$ & $2(25)$ & $22(37.3)$ & \\
\hline $5-10$ & $9(17.6)$ & $2(25)$ & $11(18.6)$ & \\
\hline $11-20$ & $11(21.6)$ & $3(37.5)$ & $14(23.7)$ & \\
\hline \multicolumn{4}{|l|}{$>20$} & \\
\hline Marital Status, n (\%) & $31(60.8)$ & $6(75)$ & $37(62.7)$ & \multirow[t]{5}{*}{$0.844^{b}$} \\
\hline Married & $11(21.6)$ & $1(12.5)$ & $12(20.3)$ & \\
\hline Single & $2(3.9)$ & $0(0)$ & $2(3.4)$ & \\
\hline Other & $7(13.7)$ & $1(12.5)$ & $8(13.6)$ & \\
\hline \multicolumn{4}{|l|}{ Did not answer } & \\
\hline Children, n (\%) & $30(58.8)$ & $6(75)$ & $36(61)$ & \multirow[t]{4}{*}{$0.634^{b}$} \\
\hline Yes & $14(27.5)$ & $1(12.5)$ & $15(25.4)$ & \\
\hline No & $7(13.7)$ & $1(12.5)$ & $8(13.6)$ & \\
\hline \multicolumn{4}{|l|}{ NA } & \\
\hline Exercise once per week, n (\%) & $25(49)$ & $2(25)$ & $27(45.8)$ & \multirow[t]{4}{*}{$0.278^{b}$} \\
\hline Yes & $17(33.3$ & $5(62.5)$ & $22(37.3)$ & \\
\hline No & $9(17.6)$ & $1(12.5)$ & $10(16.9)$ & \\
\hline NA & & & & \\
\hline
\end{tabular}

Note: ${ }^{a}$ T Independent test; ${ }^{b}$ Chi-Square test 


\begin{tabular}{|c|c|c|c|c|}
\hline & Lebanese $n=51$ & Jordanian $n=8$ & $\begin{array}{l}\text { Total } \\
\mathrm{n}=59\end{array}$ & $P$ \\
\hline Minutes of driving daily to work, $n$ (\%) & $9(17.6)$ & $3(37.5)$ & $12(20.3)$ & $0.390^{\mathrm{b}}$ \\
\hline $1-2$ hours & $26(51)$ & $2(25)$ & $28(47.5)$ & \\
\hline Less than 1 hour & $7(13.7)$ & $2(25)$ & $9(15.3)$ & \\
\hline More than 2 hours & $9(17.6)$ & $1(12.5)$ & $10(16.9)$ & \\
\hline \multicolumn{5}{|l|}{ NA } \\
\hline Governorates, n (\%) & & & 33.9 & NA \\
\hline Beirut & & & 11.9 & \\
\hline Amman & & & 28.8 & \\
\hline Mount Lebanon & & & 1.7 & \\
\hline Aqaba & & & 11.9 & \\
\hline North of Lebanon & & & 5.1 & \\
\hline South of Lebanon & & & 3.4 & \\
\hline Beqaa & & & & \\
\hline
\end{tabular}

Supplementary Table S1 illustrates the different aspects of nephrology work in both countries. The majority of the sample worked in a private setting $(71 \%)$. Jordanian nephrologists followed more transplant patients whereas Lebanese nephrologists treated more peritoneal dialysis patients. Lebanese nephrologists worked in a fewer number of hospitals than Jordanian ones $(P=0.06)$. Lebanese worked more than Jordanian nephrologists in hospitals that ensured training of medical students $(P=0.04)$. Only $3.3 \%$ worked in units run by dialysis companies and $59.3 \%$ had no desire in working in facilities managed by dialysis companies. Men spent more time in their practice than women $(P<0.001)$.

\section{Educational background and academic activities}

The majority of nephrologists in both countries were trained in general nephrology and hemodialysis. Supplementary Table S2 describes countries they graduated from, the reasons for choosing nephrology as a specialty and their current academic activities. Majority of Jordanian and Lebanese nephrologists chose this career because they found nephrology an interesting subject or field. Half of Lebanese nephrologists were influenced by their mentors, this was seen to a lesser degree in Jordan. The majority were involved in teaching, $40 \%$ did not have any publication and very few did not read regularly. There was a significant difference between female and male nephrologists regarding academic activities with 
more women spending time on teaching $(P<0.001)$, more women with academic position $(P<0.001)$ and more women with publications $(P<0.001)$.

\section{Workload}

The majority (61\%) of participants worked more than 30 hours per week (Table 2). 
Table 2

Workload of nephrologists in both countries

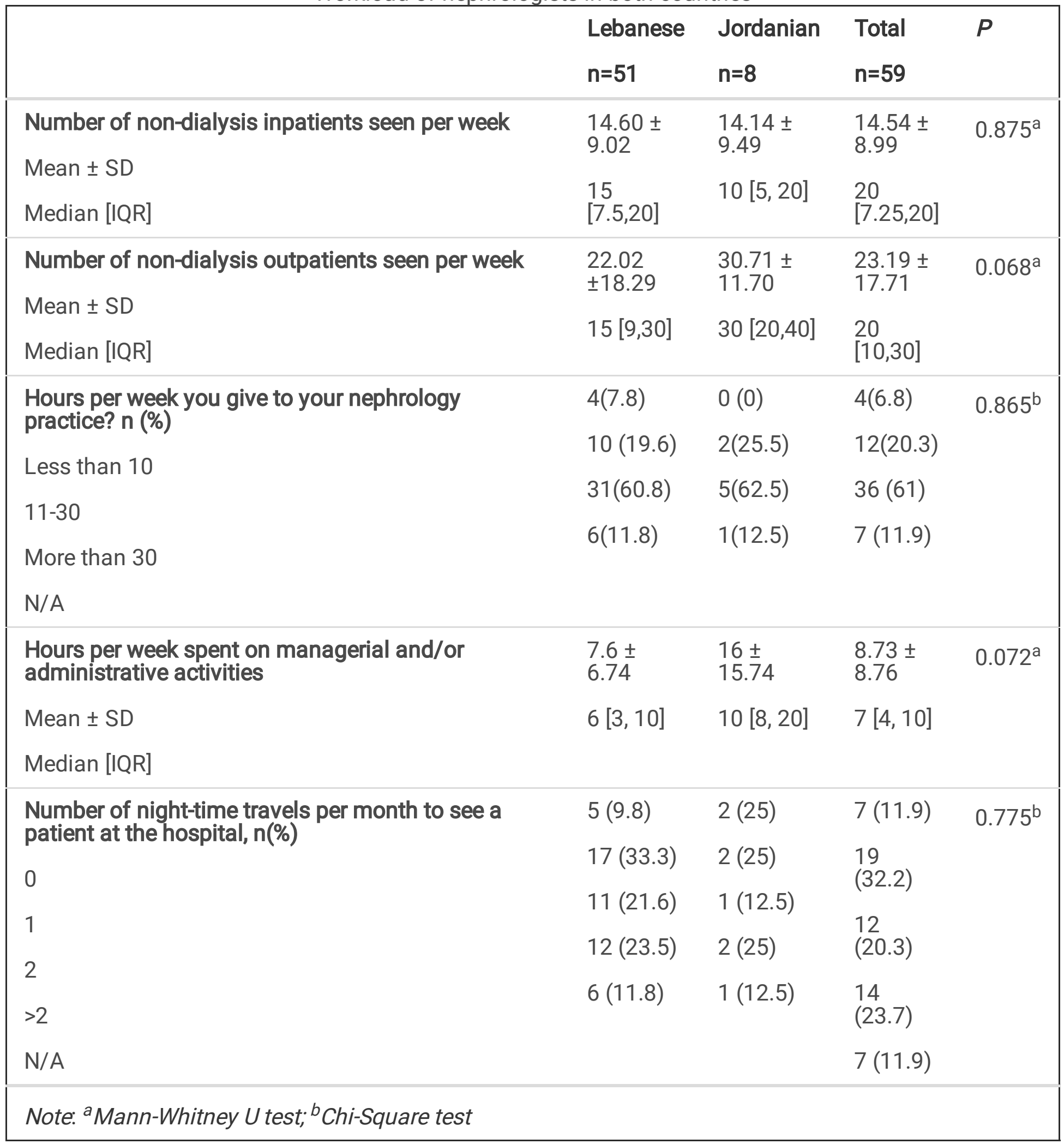

$22 \%$ of nephrologists were following more than 40 dialysis patients and $32 \%$ of them would like to follow more than 40 dialysis patients (Supplementary Table S3). When asked if fee for service was increased, only $27 \%$ would like to follow more than 40 patients (Supplementary Table S4). The main two reasons reported were avoiding loss of patients and higher financial compensation. The majority of the sample 
still preferred to follow 30-40 patients to decrease the workload. Regarding the number of dialysis units, $75 \%$ of Jordanian vs $49 \%$ of Lebanese preferred to work in more than one unit.

\section{Payment model or reimbursement}

Regarding reimbursement, $66.7 \%$ of Lebanese and $37.5 \%$ of Jordanian were paid fee-for-service only (Table 3). There was a significant difference in payment delay between Lebanon and Jordan with Lebanese being reimbursed with a mean delay of 12 months $(P=0.011)$. 
Table 3

Difference in payment characteristics between Lebanon and Jordan

\begin{tabular}{|c|c|c|c|c|}
\hline & $\begin{array}{l}\text { Lebanese } \\
\mathrm{n}=51\end{array}$ & $\begin{array}{l}\text { Jordanian } \\
n=8\end{array}$ & $\begin{array}{l}\text { Total } \\
\mathrm{n}=59\end{array}$ & $P$ \\
\hline Current reimbursement model & $3(5.9)$ & $1(12.5)$ & $4(6.8)$ & $0.369^{b}$ \\
\hline Salary & $34(66.7)$ & $3(37.5)$ & \multirow{2}{*}{$\begin{array}{l}37 \\
(62.7)\end{array}$} & \\
\hline Fee for Service & $8(15.7)$ & $3(37.5)$ & & \\
\hline Both & $6(11.8)$ & $1(12.5)$ & $\begin{array}{l}11 \\
(18.6)\end{array}$ & \\
\hline N/A & & & \multicolumn{2}{|l|}{$7(11.9)$} \\
\hline Delay in payment & $17(33.3)$ & $0(0)$ & \multirow{2}{*}{$\begin{array}{l}17 \\
(28.8)\end{array}$} & \multirow[t]{6}{*}{$0.011^{\mathrm{b}}$} \\
\hline Always & 17(33.3) & $2(25)$ & & \\
\hline Most of the time & $5(9.8)$ & $0(0)$ & $\begin{array}{l}19 \\
(32.2)\end{array}$ & \\
\hline Not at all & $6(11.8)$ & $5(62.5)$ & $5(8.5)$ & \\
\hline Sometimes & $6(11.8)$ & $1(12.5)$ & $\begin{array}{l}11 \\
(18.6)\end{array}$ & \\
\hline NA & & & $7(11.9)$ & \\
\hline Estimated time of delay (in months) & $\begin{array}{l}11.61 \pm \\
5.65\end{array}$ & $5 \pm 5.2$ & $\begin{array}{l}10.71 \pm \\
6\end{array}$ & \multirow[t]{2}{*}{$0.011^{\mathrm{a}}$} \\
\hline $\begin{array}{l}\text { Mean } \pm \text { SD } \\
\text { Median [IQR] }\end{array}$ & $\begin{array}{l}12 \\
{[9.75,17.25]}\end{array}$ & $3[0,12]$ & $\begin{array}{l}12[6, \\
12]\end{array}$ & \\
\hline Estimated current monthly income (US\$) & $5(9.8)$ & $1(12.5)$ & $6(10.2)$ & $0.999^{b}$ \\
\hline Less than 3000 & $12(23.5)$ & $2(25.5)$ & \multirow{2}{*}{$\begin{array}{l}14 \\
(23.7)\end{array}$} & \\
\hline $3000-5000$ & $21(41.2)$ & $3(37.5)$ & & \\
\hline $5000-10000$ & $7(13.7)$ & $1(12.5)$ & $\begin{array}{l}24 \\
(40.7)\end{array}$ & \\
\hline More than 10000 & & & \multicolumn{2}{|l|}{$8(13.6)$} \\
\hline If pay-for-performance (P4P) is a fee for service & $28(54.9)$ & $5(62.5)$ & $33(55.9)$ & $0.894^{b}$ \\
\hline $\begin{array}{l}\text { within recommended standards, would you prefer } \\
\text { as a payment: }\end{array}$ & 17 (33.3) & $2(25.5)$ & 19(32.2) & \\
\hline A fixed fee for service & & & & \\
\hline Pay-for-performance & & & & \\
\hline
\end{tabular}


A total of 22 questions addressed job satisfaction. Table 4 describes the continuous scores of job satisfaction of all participants. The mean overall job satisfaction score of all respondents was $3.39 \pm$ 0.45 . Cronbach's alpha was 0.833 showing a high reliability of the job satisfaction questionnaire in our sample. 
Q1 [I am satisfied with my career trajectory.]

Q2 [I have work-life balance.]

Q3 [I am satisfied with my colleagues and work environment.]

Q4 [I am satisfied with my income.]

Q5 [My current job is stressful.]

Q7 [I have a flexible work schedule.]

Q8 [I perform at my highest potential at work.]

Q9 [My salary reflects my career achievements and contributions.]

Q10 [I have regrets in choosing nephrology]

Q11 [I have a high degree of autonomy at work.]

Q12 [I view practicing medicine in academic settings as inefficient and bureaucratic.]

Q13 [There is too much pressure to secure grants, carry out research, and publish in

Q14 [The low efficiency of academic medicine is a major disincentive to work in this setting.]

Q15 [A career in academic medicine is compatible with having a family.]

Q16 [I receive adequate administrative support for my patient care activities.]

Q17 [I receive adequate support from other healthcare providers (physician assistants, nurses, medical assistants, etc.) for my patient care activities.] 


\begin{tabular}{|ll|}
\hline Question & $\begin{array}{c}\text { Mean } \\
\pm S D\end{array}$ \\
\hline Q18 [The opportunity to work with chronic patients in nephrology is appealing.] & 3.59 \\
& \pm .804 \\
\hline $\begin{array}{l}\text { Q19 [Working with interdisciplinary teams in clinical care of kidney patients is } \\
\text { rewarding.] }\end{array}$ & 3.92 \\
\hline Q20 [There is a wide variety of job opportunities for nephrologists] & 2.65 \\
& \pm 1.074 \\
\hline Q21 [I feel tired all the time.] & 3.24 \\
& \pm .929 \\
\hline Q22 [More than once a month, I skip going to work because of fatigue.] & 4.20 \\
\hline Total Satisfaction Score & \pm .775 \\
\hline Note: negative questions are given reverse scores & $3.39 \pm 0.45$ \\
\hline
\end{tabular}

Supplementary Table S5 includes the percentages of job satisfaction of nephrologists in the two countries. Participants reported low rates of satisfaction in job opportunities $(20 \%)$, income (25\%) and administrative support (32\%). On the other hand, 68\% reported that nephrology is stressful. High satisfaction rates were found in relationship with patients (78\%) and colleagues (73\%).

Questions 1 to 22 were regrouped into 9 categories in Table 5. A comparison of the mean and median scores of the two countries showed no significant difference in the job satisfaction between Lebanese and Jordanian nephrologists. 
Table 5

Job satisfaction scores grouped into 9 categories

\begin{tabular}{|c|c|c|c|c|}
\hline Category & $\begin{array}{l}\text { Lebanese } \\
\text { Mean Score } \pm \text { SD }\end{array}$ & $\begin{array}{l}\text { Jordanian } \\
\text { Mean Score } \pm \text { SD }\end{array}$ & $\begin{array}{l}\text { Total } \\
\text { Mean Score } \pm \text { SD }\end{array}$ & $P$ \\
\hline $\begin{array}{l}\text { Career and Opportunities } \\
\text { Q1 + Q10 + Q20 }\end{array}$ & $3.58 \pm 0.68$ & $3.7 \pm 0.97$ & $3.6 \pm 0.71$ & 0.657 \\
\hline $\begin{array}{l}\text { Work-life Balance } \\
\text { Q2 + Q15 }\end{array}$ & $3.36 \pm 0.73$ & $3.28 \pm 0.86$ & $3.35 \pm 0.73$ & 0.798 \\
\hline $\begin{array}{l}\text { Relationship with Colleagues } \\
\text { Q3 + Q17 + Q19 }\end{array}$ & $3.72 \pm 0.57$ & $3.71 \pm 0.80$ & $3.71 \pm 0.59$ & 0.983 \\
\hline $\begin{array}{l}\text { Income } \\
\text { Q4 + Q9 }\end{array}$ & $2.87 \pm 1.08$ & $2.71 \pm 1.22$ & $2.85 \pm 1.09$ & 0.722 \\
\hline $\begin{array}{l}\text { Academia and Research } \\
\text { Q12 + Q13 + Q14 }\end{array}$ & $2.93 \pm 0.65$ & $2.62 \pm 0.80$ & $2.89 \pm 0.67$ & 0.247 \\
\hline $\begin{array}{l}\text { Enjoying patients } \\
\text { Q6 + Q18 }\end{array}$ & $3.91 \pm 0.68$ & $4.21 \pm 0.39$ & $3.95 \pm 0.65$ & 0.262 \\
\hline $\begin{array}{l}\text { Administrative support } \\
\text { Q16 }\end{array}$ & $2.98 \pm 0.92$ & $3.57 \pm 0.97$ & $3.06 \pm 0.94$ & 0.124 \\
\hline $\begin{array}{l}\text { Autonomy and Performance } \\
\text { Q7 + Q8+Q11 }\end{array}$ & $3.67 \pm 0.65$ & $3.90 \pm 0.57$ & $3.7 \pm 0.64$ & 0.383 \\
\hline $\begin{array}{l}\text { Stress and Burnout } \\
\text { Q5 + Q21 + Q22 }\end{array}$ & $3.20 \pm 0.59$ & $2.95 \pm 0.59$ & $3.16 \pm 0.59$ & 0.298 \\
\hline
\end{tabular}

\section{Analysis of factors associated with total satisfaction score}

Using the univariate linear regression analysis, older age, more than 10 hours per week given to nephrology practice and monthly income more than 5000 US\$ were significantly associated with higher job satisfaction (Table 6). In the multivariate model, only age and weekly hours of work remained significant (Table 7). 
Table 6

Univariate regression analysis of factors associated with total satisfaction score

\begin{tabular}{|c|c|c|c|c|}
\hline & & $\begin{array}{l}\text { Unstandardized } \\
\text { Coefficient }\end{array}$ & $95 \% \mathrm{Cl}$ & $P$ \\
\hline \multirow[t]{3}{*}{ Demographics } & Age & 0.015 & $\begin{array}{l}0.006 \\
0.025\end{array}$ & 0.002 \\
\hline & Gender & -0.187 & -0.438 & 0.142 \\
\hline & Ref male & & & \\
\hline \multirow[t]{5}{*}{ Workload } & $\begin{array}{l}\text { Hours per week given to nephrology } \\
\text { practice }>10\end{array}$ & 0.648 & $\begin{array}{l}0.211 \\
1.086\end{array}$ & $0.004^{\mathrm{a}}$ \\
\hline & Ref $</=10$ & & & \\
\hline & Number of dialysis patients $>30$ & 0.168 & -0.087 & 0.193 \\
\hline & Ref $<30$ & & & \\
\hline & $\begin{array}{l}\text { Number of non-dialysis patients } \\
\text { followed weekly }\end{array}$ & 0.004 & $\begin{array}{l}-0.001 \\
0.009\end{array}$ & 0.137 \\
\hline \multirow[t]{5}{*}{ Income } & Monthly Income> 5,000 US\$ & 0.280 & 0.031 & 0.028 \\
\hline & Ref $<5,000$ USS & & & \\
\hline & Payment model (FFS) & -0.027 & -0.307 & 0.847 \\
\hline & Ref salary & & & \\
\hline & Months of delay in reimbursement & -0.007 & $\begin{array}{l}-0.029 \\
0.015\end{array}$ & 0.524 \\
\hline
\end{tabular}


Multivariate regression analysis of factors associated with total satisfaction score

\begin{tabular}{|c|c|c|c|c|}
\hline & & $\begin{array}{l}\text { Unstandardized } \\
\text { Coefficient }\end{array}$ & $95 \% \mathrm{Cl}$ & $p$ \\
\hline \multirow[t]{3}{*}{ Demographics } & Age & 0.013 & $\begin{array}{l}0.003 \\
0.024\end{array}$ & 0.014 \\
\hline & Gender & 0.057 & -0.195 & 0.653 \\
\hline & Ref male & & & \\
\hline \multirow[t]{5}{*}{ Workload } & $\begin{array}{l}\text { Hours per week given to nephrology } \\
\text { practice }>10\end{array}$ & 0.614 & $\begin{array}{l}0.187 \\
1.040\end{array}$ & 0.006 \\
\hline & $\operatorname{Ref}</=10$ & & & \\
\hline & Number of dialysis patients $>30$ & -0.006 & $\begin{array}{l}-0.290, \\
0.277\end{array}$ & 0.964 \\
\hline & Ref $<30$ & & & \\
\hline & $\begin{array}{l}\text { Number of non-dialysis patients } \\
\text { followed weekly }\end{array}$ & 0.000 & $\begin{array}{l}-0.006 \\
0.005\end{array}$ & 0.892 \\
\hline \multirow[t]{2}{*}{ Income } & Monthly Income> 5,000 US\$ & 0.160 & -0.126 & 0.265 \\
\hline & $\operatorname{Ref}<5,000$ USS & & & \\
\hline
\end{tabular}

Sub-analysis of factors related to different categories of job satisfaction

\section{Age and satisfaction towards career, income, work-life balance}

We found higher satisfaction towards career, work-life balance, income and enjoying care of patients in participants above 47 years old compared to the younger group. Only $11.8 \%$ of nephrologists younger than 40 years old were satisfied with job opportunities vs $32 \%$ above 40 . Table 8 summarizes the correlation between age and different job satisfaction components. Supplementary Figure S1 illustrates the linear regression between age and satisfaction towards income. 
Table 8

Correlation of different categories of job satisfaction with age

\begin{tabular}{|lll|}
\hline Category & $\begin{array}{l}\text { Spearman's Rho } \\
\text { Correlation Coefficient }\end{array}$ & $P$ \\
\hline Career and Opportunities & 0.431 & 0.002 \\
\hline Work-life Balance & 0.341 & 0.014 \\
\hline Relationship with Colleagues & 0.091 & 0.525 \\
\hline Satisfaction with Income & 0.388 & 0.005 \\
\hline Academia and Research & 0.099 & 0.491 \\
\hline Enjoying patients & 0.308 & 0.028 \\
\hline Administrative support & 0.266 & 0.059 \\
\hline Autonomy and Performance & 0.252 & 0.074 \\
\hline Stress and Burnout & 0.171 & 0.230 \\
\hline
\end{tabular}

\section{Workload and satisfaction with income}

Nephrologists working more than 30 hours per week tended to show higher satisfaction with income but did not reach statistical significance (mean difference $0.65,95 \% \mathrm{Cl}-1.31,0.17, P=0.056$ ). The number of hours spent on managerial activities were correlated with the stress/burnout in Jordanian nephrologists (Spearman's rho $-0.736, P=0.05$ ) but not in Lebanese nephrologists.

\section{Delay in payment and work-life balance}

The number of months of delay in payment is significantly associated with work-life balance with $P=$ 0.038 (Figure 1).

\section{Daily driving hours and satisfaction with income, work-life balance and burnout}

Driving more than one hour per day to reach work was significantly associated with dissatisfaction in work-life balance $(P=0.029)$, income $(P=0.036)$, stress and burnout $(P=0.016)$.

\section{Academic activities and job satisfaction}

When we compared nephrologists that spent less than 10 hours per year on teaching to those who spent more than 10 hours, there was no significant difference in any of the job satisfaction items. Having or not published in the last 5 years was not significantly associated with job satisfaction (association with income satisfaction $P=0.106$, mean difference $-0.52,95 \% \mathrm{Cl}-1.18,0.13$ ). 
The monthly income was significantly higher in male nephrologists than females with $33 \%$ of men earning more than 10,000 US\$ vs $4.5 \%$ women $(P<0.001)$. The satisfaction regarding income was significantly lower in female nephrologists than males with a mean score difference of $0.71 \pm 0.30$ (95\% $\mathrm{Cl} 0.10,1.32 ; P=0.024)$. When we compared workload and payment models between men and women, a higher percentage of men wanted to follow more than 40 patients $(P<0.001)$ and a higher percentage of men chose pay-for-performance over fee for service. $66.1 \%$ of the sample reported experiencing gender discrimination with no difference between Lebanon and Jordan. When comparing the two groups of men and women, gender discrimination was perceived mostly and significantly in women $(P<0.001)$.

\section{Discussion}

This is the first study that evaluates nephrologists' satisfaction in the Eastern Mediterranean Region. Contextual factors, such as workplace-related factors and work environment, can highly influence satisfaction and vary between different healthcare systems [4]. This survey of Lebanese and Jordanian nephrologists revealed low satisfaction rates regarding job opportunities (20\%), income (25\%), administrative support (32\%), research (59\%) and the majority of respondents agreed that nephrology is a stressful job. On the other hand, our results highlighted high satisfaction rates regarding relationship with patients $(78 \%)$ and colleagues $(73 \%)$. There is a paucity of data in the literature regarding job satisfaction of nephrologists worldwide and most of the studies were conducted in the US. A survey of 6590 American physicians classified nephrology as a "less satisfied" specialty [11]. Several of our satisfaction rates are aligned with those of US nephrologists [8], like the high satisfaction regarding patients, the low rate of administrative support and high agreement that nephrology is a stressful job. US nephrologists are experiencing stress and burn-out because of poor work-life balance, they are feeling unappreciated, spending a lot of time travelling between dialysis facilities that are owned by large for-profit dialysis companies and there is little of funds provided to research in nephrology $[12,13]$. The time of travel to work was also showed in our sample to be significantly associated with stress and burnout. But the satisfaction of US nephrologists is higher regarding job opportunities, income and career trajectory. Another important finding in most surveys is the low rate of regrets of choosing nephrology: $70 \%$ in the US sample and $76 \%$ in ours would choose nephrology again. A similar percentage was found in a sample of international specialists [14]. Despite the lack of regret, burnout and stress are still highly perceived for many reasons [13]. One of them is that nephrologists globally are often faced with a lot of ethical challenges regarding their chronic disease patients with dilemma regarding end-of-life care and conservative care leading to what some called "moral distress" [15].

Workload affects the satisfaction of nephrologists differently between a context and another. In Lebanese nephrologists, higher workload was not found to be associated with dissatisfaction although $60 \%$ of Lebanese reported to spend more than 40 hours weekly on patient care, a rate similar to the Jordanian group and the US surveyed nephrologists [16]. However, the number of dialysis patients per nephrologist in Lebanon is lower than other countries. And this can explain the higher satisfaction of surveyed nephrologists once the number of hours spent on nephrology practice exceeds the 10 hours weekly. One recent mixed quantitative-qualitative study done in South Africa emphasized the low density 
of nephrologists in that country and high workload [17]. In Lebanon, the abundance of physicians is an old issue, still not resolved [10]. Therefore, the higher density of nephrologists in Lebanon compared to South Africa, Jordan and the US can be a reason for the lack of significant association between workload and dissatisfaction in Lebanese nephrologists. In the Jordanian group, administrative work was correlated with more stress. The time spent on paperwork and administration is a growing burden for nephrologists worldwide and the Jordanian nephrologists are aligned with the US results [16]. US nephrologists complain of the great amount of time spent on administrative work and filling electronic medical records instead of encouraging patient-centered care [16].

Dissatisfaction regarding income is an important challenge for physicians globally, even in high-income countries. Income fairness is described as significantly associated with better job satisfaction in Japanese physicians [18]. In Saudi Arabia, a survey of physicians showed a high dissatisfaction rate regarding income [19]. In the Medscape Nephrologist Compensation Report of 2019, US nephrologists' satisfaction with income reached only $66 \%$, despite the fact that they earned 3 times more than our sample, with the same amount of workload and $44 \%$ of them were paid fee-for-service. Dissatisfaction with income is more pronounced in low and middle-income countries. In South Africa 39\% of nephrologists working in the public sector were dissatisfied with remuneration [17]. In our survey, only $25 \%$ felt that they were fairly compensated, a result that is very close to physicians in Mexico [16]. The very high density of nephrologists in Lebanon could be the reason for less income and less remuneration satisfaction. Several reforms to address this issue were suggested 15 years ago but none of them was applied [10].

Our study revealed a strong correlation between older age and some components of job satisfaction such as work-life balance, career and satisfaction with income. A study done in Norway in 2010 described also higher satisfaction rates in older doctors [20]. Another one that compared German to American physicians showed increase of job satisfaction with age [21]. However, this finding is not consistent in the literature and some authors reported better job satisfaction in younger groups of physicians [22]. Overall, young nephrologists seem to experience less satisfaction with varying degrees. Only $11.8 \%$ of our young nephrologists (<40 years old) were satisfied with job opportunities and this is much lower than the $34 \%$ in US young nephrologists [23].

The gender-based inequities between men and women are very obvious in our study. This imbalance in incomes and opportunities is reported even in developed countries like the US [24]. The higher amount of income in men physicians is emphasized also in the International Physician Compensation Report of 2019 with men specialists earning 30000-70000 \$ more than women yearly across countries like US, UK, Germany, France, Spain, Brazil and Mexico [14]. Our study showed significantly less income in women and more academic competencies. Men are those who wanted more patients in dialysis even if the reimbursement fee was increased, despite the fact that they see equal number of outpatients and inpatients. Satisfaction with income is significantly lower in women in our study. Several European studies reported statistically significant better satisfaction of male respondents compared to their female colleagues [4]. Our results highlight as well the high perception of gender discrimination in women. 
Our study has one major limitation, the low rate of respondents. This low rate of response to the survey estimated at $27 \%$ with even a lower response from Jordan of around $8 \%$. This could be related to a technical issue because the LimeSurvey appeared in the Junk mail of nephrologists. Despite this limitation, the study is very informative and is the first study to assess factors related to nephrologists' job satisfaction in the Eastern Mediterranean Region.

\section{Conclusions}

The implications of this study can be very important and need to be taken into consideration by policy makers at the level of renal societies, medical schools, orders of physicians and ministries of public health. First, it is a call for renal societies and orders of physicians in the Middle-East to support women with more job opportunities and higher income. The significant perception of discrimination towards women nephrologists should be treated first within the renal societies and women should be empowered especially that their academic contributions are significantly higher than men in our sample. Second, it is a call for medical schools to enhance and support the role of mentorship because it is found influential towards the choice of specialty of physicians. Medical schools in collaboration with the ministry of public health have the obligation of assessing the needs of a nation in terms of number of specialists and prevent the high density of nephrologists. Third, when facing a high number of nephrologists, policy makers should consider the increase in reimbursement fee of dialysis sessions that may lead, based on our results, to a lower number of patients followed by each physician and less workload on nephrologists. Advocacy against delay in payments is a must to achieve better work-life balance of physicians. Finally, the very low satisfaction of young nephrologists towards job opportunities indicates the very deep conundrum that we are facing in our region. This requires urgently a revision of regulations and policies and limiting the number of nephrologists trained within or imported to the country as long as work opportunities are not guaranteed.

\section{Abbreviations}

FFS

Fee For Service

\section{Declarations}

\section{- Ethics approval and consent to participate}

This study got the approval of the Institutional Review Board of the American University of Beirut (IRB number SBS-2019-0481).

\section{- Consent for publication}

Not applicable 
- Availability of data and materials

All data generated or analyzed during this study are included in this published article [and its supplementary information files].

\section{- Competing interests}

The authors declare that they have no competing interests

\section{- Funding}

No funding

\section{- Authors' contributions}

MA, NB and KK contributed to the design conceptualization. MA and NB worked on the data acquisition and analysis and MA performed the statistical analysis. MA and NB developed the first draft of the manuscript. KK revised the manuscript. All authors read and approved the final manuscript.

\section{- Acknowledgements}

We would like to acknowledge all nephrologists who participated to this study.

\section{- Authors' information}

Mabel Aoun, MD, MPH is an Assistant Professor at the Medical School of Saint-Joseph University and Head of Department of Nephrology at Saint-Georges Ajaltoun Hospital as well as an MPH graduate from the American University of Beirut; Nour Breiteh, MPH is a public health professional graduate from the American University of Beirut; Kassem Kassak is an Associate Professor of Public Health Practice in the Department of Health Management and Policy, and Director of the Executive Master in Health Care Leadership at the Faculty of Health Science of the American University of Beirut.

\section{References}

1. Tran BX, Van Hoang M, Nguyen HD. Factors associated with job satisfaction among commune health workers: implications for human resource policies. Glob Health Action. 2013;6:1-6. doi:10.3402/gha.v6i0.18619.

2. Wallace JE, Lemaire JB, Ghali WA. Physician wellness: A missing quality indicator. Lancet. 2009;374:1714-21.

3. Scheepers RA, Boerebach BC, Arah OA, Heineman MJ, Lombarts KM. A Systematic Review of the Impact of Physicians' Occupational Well-Being on the Quality of Patient Care. Int J Behav Med. 2015;22:683-98. 
4. Domagala A, Bala MM, Storman D, et al. Factors Associated with Satisfaction of Hospital Physicians: A Systematic Review on European Data. Int J Environ Res Public Health. 2018;15:2546. doi:10.3390/ijerph15112546.

5. Williams E, Skinner A. Outcomes of physician job satisfaction: A narrative review, implications, and directions for future research. Health Care Manag Rev. 2003;28:119-40.

6. de Boer IH. Nephrology at a Crossroads. Clin J Am Soc Nephrol. 2018;13(2):324. doi:10.2215/CJN.09070817.

7. Gu X, Itoh K. Construct of dialysis employee satisfaction: acquiring satisfaction factors and their contributions. Therapeutic Apheresis Dialysis. 2015;19(5):503-12.

8. McMahon GM, Thomas L, Tucker JK, Lin J. Factors in Career Choice among US nephrologists. Clin J Am Soc Nephrol. 2012;7:1786-92. doi:10.2215/CJN.03250312.

9. Shah HH, Jhaveri KD, Sparks MA, Mattana J. Career Choice Selection and Satisfaction among US Adult Nephrology Fellows. Clin J Am Soc Nephrol. 2012;7:1513-20. doi:10.2215/CJN.01620212.

10. Kassak KM, Ghomrawi HMK, Osseiran AMA, Kobeissi $\mathrm{H}$. The providers of health services in Lebanon: a survey of physicians. Human Resources for Health. 2006;4:4. doi:10.1186/1478-4491-4-4.

11. Leigh JP, Tancredi DJ, Kravitz RL. Physician career satisfaction within specialties. BMC Health Serv Res. 2009;9:166. https://doi.org/10.1186/1472-6963-9-166.

12. Rosner MH, Berns JS. Transforming Nephrology. Clin J Am Soc Nephrol. 2018;13(2):331-4. DOl:https://doi.org/10.2215/CJN.02310317.

13. Roberts JK. Burnout in Nephrology. Implications on Recruitment and the Workforce. Clin J Am Soc Nephrol. 2018;13:328-30. doi:https://doi.org/10.2215/CJN.09870917.

14. Kane L. International Physician Compensation Report 2019: Do US Physicians Have It Best? Available at: https://www.medscape.com/slideshow/2019-international-compensation-report$6011814 \# 5$.

15. Ducharlet K, Philip J, Gock H, et al. Moral Distress in Nephrology: Perceived Barriers to Ethical Clinical Care. Am J Kidney Dis; 2019;pii: S0272-6386(19)31121-7. doi: 10.1053/j.ajkd.2019.09.018.

16. Kane L. Medscape Nephrologist Compensation Report 2019. Available at: https://www.medscape.com/slideshow/2019-compensation-overview-6011286.

17. Hassen M, Archer E, Pellizzon A, Chikte UM, Davids MR. Human resources for nephrology in South Africa: A mixed-methods study. PloS One. 2020;15(2):e0228890.

18. Wada K, Arimatsu M, Higashi T, et al. Physician job satisfaction and working conditions in Japan. J Occup Health. 2009;51(3):261-6. https://doi.org/10.1539/joh.08023.

19. Aldrees T, Al-Eissa S, Badri M, Aljuhayman A, Zamakhshary M. Physician job satisfaction in Saudi Arabia: insights from a tertiary hospital survey. Ann Saudi Med. 2015;35(3):210-3. https://doi.org/10.5144/0256-4947.2015.210.

20. Aasland OG, Rosta J, Nylenna M. Healthcare reforms and job satisfaction among doctors in Norway. Scand J Public Health. 2010;38(3):253-8. doi:10.1177/1403494810364559. 
21. Janus K, Amelung VE, Baker LC, Gaitanides M, Schwartz FW, Rundall TG. Job satisfaction and motivation among physicians in academic medical centers: Insights from a cross-national study. $J$ Health Politics Policy Law. 2008;33:1133-67.

22. Mascia D, Morandi F, Cicchetti A. Hospital restructuring and physician job satisfaction: An empirical study. Health Policy. 2014;114:118-27.

23. Quigley L, Salsberg E, Collins A. Report on a Survey of Nephrologists in Early Years of Practice. Washington, DC: American Society of Nephrology; 2018. https://www.asnonline.org/education/training/workforce/Nephrology_Early_Career_Survey_Report_2018.pdf.

24. Hoff T, Scott $S$. The gendered realities and talent management imperatives of women physicians. Health Care Manage Rev. 2016;41(3):189-99. doi:10.1097/HMR.0000000000000069.

\section{Figures}

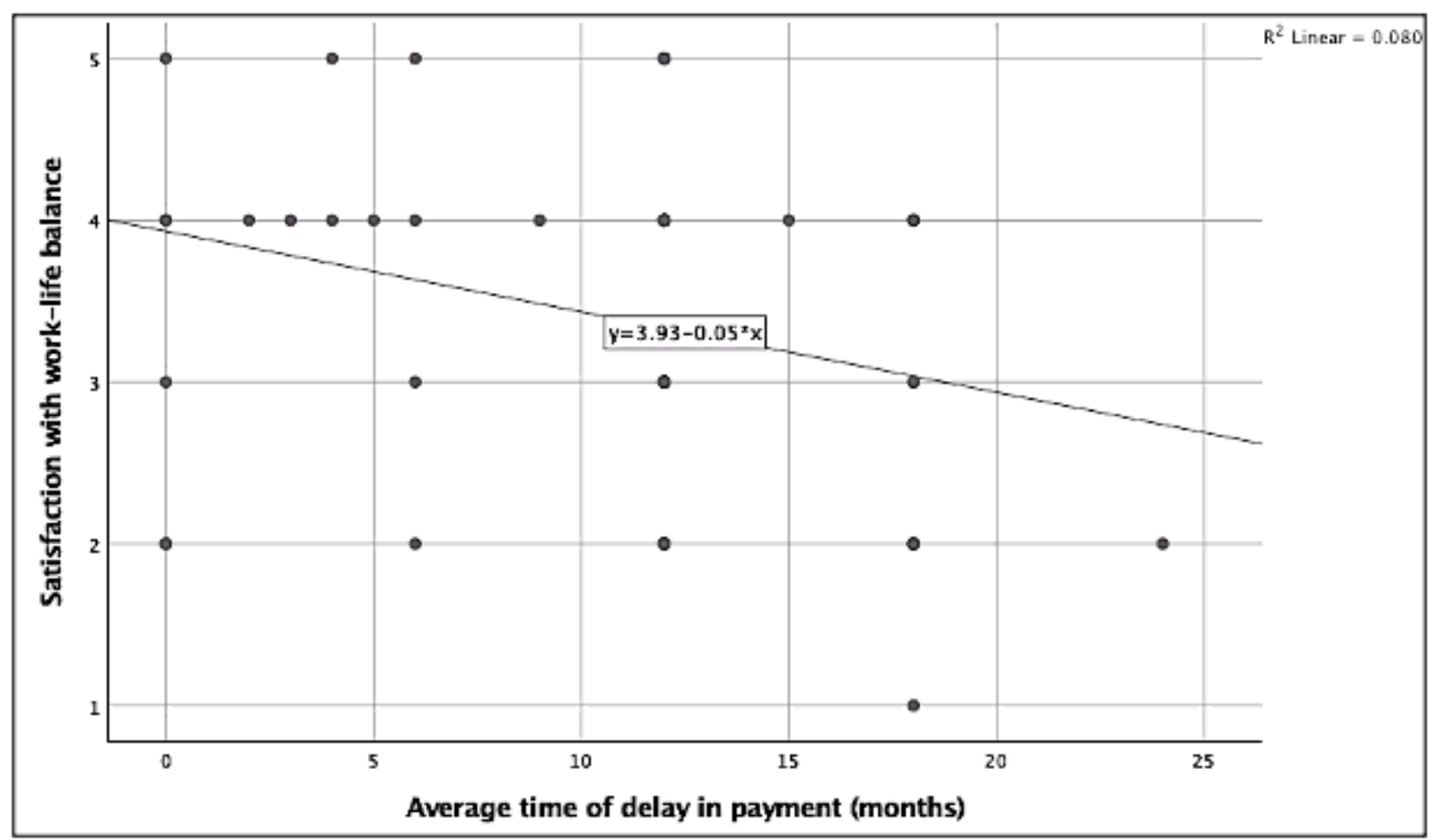

\section{Figure 1}

Linear regression between number of months of delay in payment and work-life balance satisfaction 